\title{
PROBLEMATIKA PEMBANGUNAN KARAKTER DAN SOLUSINYA
}

\author{
Fatma Raudhah \\ Dosen Bahasa Pusat Pengembangan Bahasa Institut Agama Islam Negeri \\ Padangsidimpuan \\ Jalan T. Rizal Nurdin KM. 4,5 Sihitang Padangsidimpuan \\ E-mail: fatmaraudhah01@yahoo.com
}

\begin{abstract}
Abstrak
Dalam pembangunan karakter terdapat beberapa problematika, di antaranya adalah memudarnya nasionalisme dan jati diri bangsa, merosotnya harkat dan martabat bangsa, mentalitas bangsa yang buruk, krisis multidimensial, dan degradsi moral perusak bangsa. Solusi pembangunan karakter adalah meningkatkan rasa kebangsaan dan kesadaran berbangsa, penerapan pendidikan karakter dalam Pendidikan Islam, penggunaan metode-metode pendidikan karakter dalam Pendidikan Islam. Metode yang digunakan adalah: metode tarbiyah, metode ta'dîb, metode tazkiyah, dan metode tadlrîb (latihan).

Abtract

In character building there are several problems, including the waning of nationalism and national identity, the decline of national dignity and dignity, poor national mentality, multidimential crisis, and the degradation of the moral destroyer of the nation. The character building solution is to increase nationalism and national awareness, the application of character education in Islamic Education, the use of methods of character education in Islamic Education. The methods used are: tarbiyah method, ta'dîb method, tazkiyah method, and tadlrib (practice) method.
\end{abstract}

Kata Kunci: Problematika, Karakter, dan Solusi 


\section{Fatma Raudhah}

\section{Pendahuluan}

Dewasa ini, bangsa Indonesia sedang menghadapi permasalahan fondamental dalam kehidupan berbangsa dan bernegara. Permasalahan itu berupa perilaku masyarakat belum sejalan dengan karakter bangsa yang dijiwai oleh falsafah Pancasila: religius, humanis, nasionalis, demokratis, keadilan dan kesejahteraan rakyat. Jika permasalahan ini dibiarkan dapat menimbulkan ancaman pada eksistensi bangsa. Karena itu diperlukan pendidikan karakter yang berfungsi untukmengembangkan potensi dasar berhati, berpikiran dan berperilaku baik, memperbaiki perilaku yang kurang baik dan menguatkan perilaku yg sudah baik, menyaring budaya yg kurang sesuai dengan nilai-nilai luhur Pancasila.

Istilah nation and charakter building adalah istilah klasik dan menjadi kosa kata hampir sepanjang sejarah modern Indonesia terutama sejak peristiwa Sumpah Pemuda 1928. Istilah ini mencuat kembali sejak tahun 2010 ketika pendidikan karakter dijadikan sebagai gerakan nasional pada puncak acara Hari Pendidikan Nasional 20 Mei 2010. Latar belakang munculnya pendidikan karakter ini dilatarbelakangi oleh semakin terkikisnya karakter sebagai bangsa Indonesia, dan sekaligus sebagai upaya pembangunan manusia Indonesia yang berakhlak budi pekerti yang mulia.

Pendidikan karakter adalah proses kegiatan yang dilakukan dengan segala daya dan upaya secara sadar dan terencana untuk mengarahkan anak didik. Pendidikan karakter juga merupakan proses kegiatan yang mengarah pada peningkatan kualitas pendidikan dan pengembangan budi harmoni yang selalu mengajarkan, membimbing, dan membina setiap menusiauntuk memiliki kompetensi intelektual, karakter, dan keterampilan menarik. Nilai-nilai pendidikan karakter yang dapat dihayati dalam penelitian ini adalah religius, nasionalis, cerdas, tanggung jawab, disiplin, mandiri, jujur, dan arif, hormat dan santun, dermawan, suka menolong,

${ }^{1}$ Heri Gunawan, Pendidikan Karakter Konsep dan Implementasi. (Bandung: Alfabeta, 2012), hlm 30 
gotong-royong, percaya diri, kerja keras, tangguh, kreatif, kepemimpinan, demokratis, rendah hati, toleransi, solidaritas dan peduli. ${ }^{2}$

Definisi dari "The stamp of individually or group impressed by nature, education or habit. Karakter merupakan nilai-nilai perilaku manusia yang berhubungan dengan Tuhan Yang Maha Esa, diri sendiri, sesama manusia, lingkungan, dan kebangsaan yang terwujud dalam pikiran, sikap, perasaan, perkataan, dan perbuatan berdasarkan norma-norma agama, hukum, tata krama, budaya, dan adat istiadat. Karakter dapat juga diartikan sama dengan akhlak dan budi pekerti, sehingga karakter bangsa identik dengan akhlak bangsa atau budi pekerti bangsa. Bangsa yang berkarakter adalah bangsa yang berakhlak dan berbudi pekerti, sebaliknya bangsa yang tidak berkarakter adalah bangsa yang tidak atau kurang berakhlak atau tidak memiliki standar norma dan perilaku yang baik ${ }^{3}$.

\section{Problematika Pembagunan Karakter}

Problematika pembagunan karakter ditandai oleh beberapa hal sebagai berikut:

\section{Memudarnya Nasionalisme dan Jati Diri Bangsa}

Nasionalisme secara umum berarti cinta tanah air, bangsa dan negara dan rela berjuang dan berkorban untuk kejayaannya. Dalam nasionalisme ada heroisme, altruisme dan patriotisme dan mengesampingkan individualisme, hedonisme dan anti sparatisme.

Dalam kehidupan berbangsa dan bernegara akhir-akhir ini, jiwa nasionalisme Indonesia semakin terkikis atau semakin memudar, yang ditandai dengan berkembangnya semangat individualisme, hedonisme, terorisme dan bahkan sparatisme. Tanda-tanda kerkikisnya nasionalisme ini melanda hampir semua komponen bangsa baik muda maupun tua, rakyat biasa maupun pejabat negara termasuk kalangan anggota dewan. Bilan angkatan 45 dianggap sebagai generasi pejuang, angkatan 66 sebagai

${ }^{2}$ Yahya Khan, Pendidikan Karakter Berbasis Potensi Diri, (Yogyakarta : Pelangi Publishing, 2010), hlm 34

${ }^{3}$ Tobroni, Pendidikan Islam, Paradigma Teologis, Filosofis dan Spiritualitas Malang: UMM Press, 2008, thl. 


\section{Fatma Raudhah}

generasi pembangun, dan angkatan 98 sampai sekarang adalah generasi penikmat dan bahkan penghancur.

Untuk berebut menjadi pejabat publik, anggota dewan, pegawai negeri, polisi dan bahkan TNI dari tingkat rendah sampai pejabat tinggi harus membayar dengan sejumlah uang. Setelah tercapai apa yang diinginkan, lantas dengan berbagai cara agar uang yang telah dikeluarkan segera kembali, dan menggunakan fasilitas negara, wewenang dan hak-hak istimewanya (privilege) untuk memperkaya diri, memperkuat posisi dan menciptakan hegemoni. Mereka bukan sebagai abdi negara melainkan penghianat negara, bukan pejuang melainkan pecundang. Disamping itu masih ada fenomena terkikisnya nasionalisme yang lain yaitu munculnya sparatisme, terorisme, dan berkembangnya ideologi trans-nasional yang mengingkari paham kebangsaan, cinta tanah air dan negara. Fenomena lain dari terkikisnye nasionalisme adalah enggan memakai produksi dalam negeri, baik dalam bentuk makanan, pakaian, dan teknologi.

\section{Merosotnya Harkat dan Martabat Bangsa}

Indonesia sejatinya adalah bangsa dan negara besar: negara kepulauan terbesar di dunia, jumlah umat muslim terbesar di dunia, bangsa multi etnik dan bahasa namun bersatu, memiliki warisan sejarah yang menakjubkan dan kreatifitas anak negeri seperti batik, aneka makanan dan kerajinan yang eksotik, kekayaan serta keindahan alam yang luar biasa. Predikat sebagai bangsa dan negara yang positip itu seakan sirna karena mendapat predikat baru yang negatip seperti terkorup, bangsa yang soft nation, malas, sarang teroris, bangsa yang hilang keramah tamahannya, banyak kerusuhan, banyak bencana dan lain sebagainya.

Fenomena lain dari merosotnya harkat dan martabat bangsa adalah seperti yang ditakutkan Sukarno, "menjadi bangsa kuli dan kuli di antara bangsa-bangsa."Bahkan, mungkin yang lebih buruk lagi dari kekuatiran Sukarno, "menjadi bangsa pengemis dan pengemis di antara bangsabangsa"4. Bangsa Indonesia barangkali adalah negara pengekspor

4Basari, Hasan / Bernhard Dahm, Sukarno dan perjuangan kemerdekaan, Jakarta: LP3ES, 1987. Judul asli : Sukarno and the struggle for Indonesia. 
kuli/babu/tenaga kasar/unskill terbesar di dunia. TKI TKW kita diperlukan di negara-negara tujuan tetapi sangat tidak dihargai dan sering diperlakukan sebagai budak dan perlakuan yang tidak manusiawi lainnya. TKI/TKW memang dapat meningkatkan devisa negara, tetapi sesungguhnya madlorotnya lebih besar dari pada manfaatnya, termasuk merosotnya harkat dan martabat bangsa.

\section{Mentalitas Bangsa yang Buruk}

Indonesia memiliki modal atau kekuatan yang memadai untuk menjadi bangsa besar dan negara yang kuat. Modal itu antara lain: luas wilayah, jumlah penduduk, kekayaan alam, kekayaan budaya, kesatuan bahasa, ketaatan pada ajaran agama, dan sistem pemerintahan republik yang demokratis. Akan tetapi modal yang besar itu seakan tidak banyak berarti apabila mentalitas bangsa ini belum terbangun atau belum berubah ke arah yang lebih baik. Mentalitas bangsa Indonesia yang kurang kondusif atau menjadi penghambat kejayaan bangsa Indonesia menjadi bangsa maju antara lain: malas, tidak disiplin, suka melanggar aturan, ngaji pumpung, suka menerabas, dan nepotisme.

Selama mental sebuah bangsa tersebut tidak berubah, maka bangsa tersebut juga tidak akan mengalami perubahan dan akan tertinggal dengan bangsa-bangsa lain, meskipun bangsa tersebut sesungguhnya memiliki potensi dan modal yang besar. Allah dalam hal ini secara tegas mengatakan: "Sesungguhnya Allah tidak mengubah keadaan sesuatu kaum sehingga mereka mengubah keadaan yang ada pada diri mereka sendiri (QS. 13:11).

Media yang paling ampuh untuk merubah mentalitas bangsa adalah lewat pendidikan dan keyakinan agama. Pendidikan yang mampu merubah mentalitas adalah pendidikan yang dilaksanakan dengan sungguh-sungguh dan sepenuh hati, bukan hanya sekedar formalitas atau kepura-puraan. Keyakinan agama juga besar pengaruhnya bagi mentalitas bangsa. Karena itu melalui pendidikan agama yang mampu menanamkan keimanan yang benar, ibadah yang benar dan akhlakul karimah, niscaya akan menjadikan anak didik sebagai manusia terbaik, yaitu yang bermanfaat bagi orang alain melalui amal shalehnya.

\section{Krisis Multidimensional}




\section{Fatma Raudhah}

Berbagai permasalahan menimpa Bangsa Indonesia seperti masih adanya konflik sosial di berbagai tempat, sering mengedepankan cara kekerasan dalam menyelesaikan berbagai permasalahan, praktek korupsi yang semakin canggih dan massif, sering terjadi perkelahian antar pelajar, pelanggaran etika dan susila yang semakin vulgar, munculnya aliran yang dianggap sesat dan cara-cara penyelesaiannya yang cenderung menggunakan kekerasan, tindakan kejahatan yang mengancam ketenteraman dan keamanan, praktek demokrasi liberal yang ekstreem dalam berbagai aspek kehidupan sehingga bertabrakan dengan budaya dan nilai-nilai kepatutan sebagai bangsa Timur dan bangsa yang religius.

Sebagai bangsa Muslim terbesar di dunia, Indonesia juga masih menghadapi persoalan yang serius dalam kehidupan berbangsa dan bernegara, antara lain masih adanya sebagian umat Islam yang belum at home sebagai Bangsa Indonesia. Mereka belum sepenuhnya menerima keberadaan Negara Kesatuan Republik Indonesia yang berdasar Pancasila dan Undang-Undang Dasar 1945 sebagai bentuk negara yang final. Masih adanya sebagian umat yang belum memiliki kemampuan dan keterampilan untuk hidup bersama dalam keberbedaan. Dampak dari sikap itu antara lain berupa masih kuatnya eksklusifitas, maraknya gerakan-gerakan umat yang kontra produktif, seperti terorisme, garakan-gerakan bawah tanah yang bertujuan mengganti bentuk negara, berbagai bentuk pembangkangan dan bahkan perlawanan terhadap negara dan pemerintahan yang sah. Akibat dari sikap sebagian umat Islam ini sangat luas, berangkai dan kontra produktif bagi bangsa dan negara, dan khususnya bagi umat Islam ${ }^{5}$.

Permasalahan yang serius juga terjadi di dunia pendidikan. Pelanggaran etika sosial dan susila serta kekerasan dalam berbagai bentuknya sering terjadi seperti: perkelaian antar pelajar, seks bebas, tindak pidana, sikap tidak etis terhadap guru, berbagai bentuk pelanggaran tata tertib sekolah, dan minimnya prestasi dan kejayaan yang dicapai para pelajar kita.

5.------, Rekonstruksi Pendidikan Agama untuk Membangun Etika Sosial dalam Kehidupan Berbangsa dan Bernegara, (Malang: UMM Press, 2010). 
Permasalahan bangsa tersebut di atas semakin diperparah dengan tayangan telivisi yang sangat vulgar, life, tidak mengenal waktu tayang, dan diulang-ulang oleh hampir semua stasiun TV dan juga surat kabar. Peristiwa pembunuhan, pemerkosaan, perkelaian, perampokan, pembakaran, demo yang anarkis, tidakan aparat yang represif, perceraian, terorisme dan berbagai bentuk tindakan kejahatan justru menjadi menu utama dan disiarkan dalam berbagai bentuk tayangan (berita, peristiwa, sinetron, dialog dan lain-lain). Semboyan wartawan adalah "bad news is good news". Berita baik apabila ada unsur 'blood" dan "crowd". Tindakan memperolok, memfitnah, menghina, mengadu domba, pembunuhan karakter justru difasilitasi oleh media.

Fenomena di atas, apabila kita renungkan akan menimbulkan keprihatinan yang mendalam. Prihatin terhadap kualitas generasi muda di masa depan, prihatin terhadap citra dan daya saing bangsa kita yang semakin rendah dan direndahkan oleh bangsa-bangsa lain. Kita juga prihatin terhadap stigma terhadap sebagian umat Islam yang diidentikkan dengan teroris, anti intelektual dan anti peradaban.

Berbagai permasalahan tersebut diasumsikan bersumber dari krisis etika dan moral: bisa korupsi dianggap prestasi, penipuan dianggap lumrah asalkan tidak keterlaluan, hilangnya budaya malu (marwah), hilangnya keperawanan tidak lagi disesalkan, politik uang untuk membeli kekuasaan, berbudi bahasa yang santun dianggap suatu kelemahan, agama tidak lagi dipedomani sebagai akhlak melainkan sebagai alat kepentingan dan kekuasaan, dan bahasa kekerasan adalah bahasa kekuasaan dan ketertindasan.

Adanya krisis etika dan moral dalam kehidupan bermasyarakat, berbangsa dan bernegara, bahkan juga krisis etika dan moral dalam beragama lantas memunculkan pertanyaan tentang peranan dan sumbangan Pendidikan Agama Islam (PAI) dalam membentuk etika dan moral. Walaupun variabel perkembangan permasalahan tersebut sesungguhnya sangat kompleks, namun seringkali secara langsung maupun tidak langsung dihubungkan dengan permasalahan pendidikan agama di sekolah. Pertanyaan seperti ini dianggap sah-sah saja karena sumber dari 


\section{Fatma Raudhah}

berbagai permasalahan tersebut adalah akibat adanya krisis etika dan moral, sedangkan tugas pokok pendidikan agama adalah membentuk anak didik memiliki moralitas dan akhlak budi pekerti yang mulia ${ }^{6}$.

Kondisi tersebut tentu saja sangat memprihatinkan. Kondisi ini menuntut semua pihak untuk mengambil peran masing-masing guna menyelamatkan generasi muda dan bangsa. Kaum agamawan sebagai penjaga etika dan moral masyarakat termasuk di dalamnya guru agama harus diberdayakan agar dapat mengambil peran secara signifikan. Demikian juga pendidikan agama yang memiliki peran strategis harus semakin ditingkatkan mutu dan relevansinya bagi upaya pembangunan moral bangsa. Pendidikan agama di sekolah perlu direkonstruksi agar dapat memerankan tugas dan fungsinya secara efektif yaitu membangun akhlak (etika dan moral) generasi penerus bangsa. Rekonstruksi itu meliputi aspek filosofis, substantif dan metodologis.

\section{Degradasi Moral Perusak Karakter Bangsa}

Eksistensi, kemuliaan dan kejayaan sebuah bangsa tergantung akhlaknya, demikian juga keterpurukan, kehinaan dan kehancurannya. Awal dan sumber segala kebaikan adalah akhlak, demikian juga segala keburukan bersumber dan bermuara kepada akhlak. Apabila sebuah bangsa mengalami krisis moral dan akhlak, maka bangsa tersebut akan berbuat dlalim, berbuat kerusakan terhadap alam maupun kedlaliman terhadap sesamanya. Dampak dari kedlaliman tersebut adalah timbulnya berbagai musibah, balak dan bencana, baik yang bersumber dari alam seperti maupun manusia. Seorang psikolog dan ahli pendidikan Amerika bernama Thomas Lichona mengidentifikasi adanya 10 tanda-tanda degradasi moral yang dapat merusak karakter bangsa ${ }^{7}$. Degradasi moral itu ialah:

1. Memeningkatnya kekerasan pada remaja

2. Penggunaan kata-kata yang memburuk

6-------, Rekonstruksi Pendidikan Agama untuk Membangun Etika Sosial dalam Kehidupan Berbangsa dan Bernegara, (Malang: UMM Press, 2010)

${ }^{7}$ Thomas Lichona, www.cortland.edu/character/aboutus.htm, diakses April 2016. 
3. Pengaruh peer group (rekan kelompok) yang kuat dalam tindak kekerasan

4. Meningkatnya penggunaan narkoba, alkohol dan seks bebas

5. kaburnya batasan moral baik-buruk

6. Menurunnya etos kerja

7. Rendahnya rasa hormat kepada orang tua dan guru

8. Rendahnya rasa tanggung jawab individu dan warga negara

9. Membudayanya ketidakjujuran.

10. Adanya saling curiga dan kebencian diantara sesama.

\section{Solusi Pembangunan Karakter}

Adapun solusi dalam pembagunan karakter yang ditawarkan oleh penulis sebagai berikut:

\section{Meningkatkan Rasa Kebangsaan dan Kesadaran Berbangsa}

Setiap orang tentu memiliki rasa kebangsaan dan memiliki wawasan kebangsaan dalam perasaan atau pikiran, paling tidak di dalam hati nuraninya. Dalam realitas, rasa kebangsaan itu seperti sesuatu yang dapat dirasakan tetapi sulit dipahami. Namun ada getaran atau resonansi dan pikiran ketika rasa kebangsaan tersentuh. Rasa kebangsaan bisa timbul dan terpendam secara berbeda dari orang per orang dengan naluri kejuangannya masing-masing, tetapi bisa juga timbul dalam kelompok.

Rasa kebangsanaan adalah kesadaran berbangsa, yakni rasa yang lahir secara alamiah karena adanya kebersamaan sosial yang tumbuh dari kebudayaan, sejarah, dan aspirasi perjuangan masa lampau, serta kebersamaan dalam menghadapi tantangan sejarah masa kini. Dinamisasi rasa kebangsaan ini dalam mencapai cita-cita bangsa berkembang menjadi wawasan kebangsaan, yakni pikiran-pikiran yang bersifat nasional dimana suatu bangsa memiliki cita-cita kehidupan dan tujuan nasional yang jelas. Berdasarkan rasa dan paham kebangsaan itu, timbul semangat kebangsaan atau semangat patriotisme. 


\section{Fatma Raudhah}

Adapun ciri-ciri bangsa yang karakter menurut Soekarno adalah sebagai ${ }^{8}$.

a. Pertama, Kemandirian (self-reliance), atau menurut istilah Presiden Soekarno adalah "Berdikari" (berdiri di atas kaki sendiri). Dalam konteks aktual saat ini, kemandirian diharapkan terwujud dalam percaya akan kemampuan manusia dan penyelenggaraan Republik Indonesia dalam mengatasi krisis-krisis yang dihadapinya.

b. Kedua, Demokrasi (democracy), atau kedaulatan rakyat sebagai ganti sistem kolonialis. Masyarakat demokratis yang ingin dicapai adalah sebagai pengganti dari masyarakat warisan yang feodalistik. Masyarakat di mana setiap anggota ikut serta dalam proses politik dan pengambilan keputusan yang berkaitan langsung dengan kepentingannya untuk mencapai kesejahteraan dan kemakmuran.

c. Ketiga, Persatuan Nasional (national unity). Dalam konteks aktual dewasa ini diwujudkan dengan kebutuhan untuk melakukan rekonsiliasi nasional antar berbagai kelompok yang pernah bertikai ataupun terhadap kelompok yang telah mengalami diskriminasi selama ini.

d. Keempat, Martabat Internasional (bargaining positions). Indonesia tidak perlu mengorbankan martabat dan kedaulatannya sebagai bangsa yang merdeka untuk mendapatkan prestise, pengakuan dan wibawa di dunia internasional. Sikap menentang hegemoni suatu bangsa atas bangsa lainnya adalah sikap yang mendasari ide dasar "nation and character building." Bung Karno menentang segala bentuk "penghisapan suatu bangsa terhadap bangsa lain," serta menentang segala bentuk "neokolonialisme" dan "neoimperialisme." Indonesia harus berani mengatakan "tidak" terhadap tekanantekanan politik yang tidak sesuai dengan "kepentingan nasional" dan "rasa keadilan" sebagai bangsa merdeka.Hampir sama dengan gagasan Soekarno, penulis mengemukakan bangsa yang berkarakter

${ }^{8}$ Basari, Hasan / Bernhard Dahm, Sukarno dan perjuangan kemerdekaan, Jakarta : LP3ES, 1987. Judul asli Sukarno and the struggle for Indonesia. 
memiliki ciri-ciri sebagai berikut ${ }^{9}$. Berpegang teguh pada nilai budaya dan agamanya serta demokratis dan multikultural

e. Mencintai dan rela berkorban untuk bangsa dan negaranya

f. Menjunjung tinggi hukum dan peraturan yang berlaku (tidak soft nation)

g. Memiliki integritas moral dan intelektual, dedikasi, etos kerja dan altruistik

\section{Penerapan Pendidikan Karakter Dalam Pendidikan Isalm}

Sebagaimana dikemukakan di muka, bahwa puncak karakter seorang muslim adalah taqwa, dan indikator ketaqwaannya adalah terletak pada akhlaknya. Manusia (bangsa) yang berkarakter dalam perspektif seorang Muslim digambarkan sebagai berikut ${ }^{10}$ :

Karakter dibangun berdasarkan pemahaman tentang hakikat dan struktur kepribadian manusia secara integral. Sehingga manusia berkarakter taqwa adalah gambaran manusia ideal yaitu manusia yang memiliki kecerdasan spiritual (spiritual quotient). Kecerdasan spiritual inilah yang seharusnya paling ditekankan dalam pendidikan. Hal ini dilakukan dengan penanaman nilai-nilai etis religius melalui keteladanan dari keluarga, sekolah dan masyarakat, penguatan pengamalan peribadatan, pembacaan dan penghayatan kitab suci Al-Qur'an, penciptaan lingkungan baik fisik maupun sosial yang kondusif. Apabila spiritualitas anak sudah tertata, maka akan lebih mudah untuk menata aspek-aspek kepribadian lainnya.

Maksudnya, kalau kecerdasan spiritual anak berhasil ditingkatkan, secara otomatis akan meningkatkan kecerdasan-kecerdasan lainnya seperti kecerdasan emosional (emotional quotient), kecerdasan memecahkan masalah (adversity quotient) dan kecerdasan intelektual (intellectual quotient). Inilah sebenarnya kunci mengapa aktifitas pendidikan yang berbasis agama lebih banyak berhasil dalam membentuk kepribadian anak.

${ }^{9}$ Basari, Hasan / Bernhard Dahm, Sukarno dan perjuangan kemerdekaan, Jakarta : LP3ES, 1987. Judul asli : Sukarno and the struggle for Indonesia. ttl.

10. Tobroni, Pendidikan Islam, Paradigma Teologis, Filosofis dan Spiritualitas Malang: UMM Press, 2008. $\mathrm{ttl}$ 


\section{Fatma Raudhah}

Keterpaduan, keserasian dan pencahayaan Godspot (ruh) terhadap kalbu, akal dan nafsu dan jasad jelas akan memaksimalkan kecerdasan dan fungsi masing-masing. Dalam konteks tujuan pendidikan, hal ini akan mampu membentuk anak didik yang memiliki kekokohan akidah (quwwatul aqidah), kedalaman ilmu (quwwatul ilmi), ketulusan dalam pengabdian (quwwatul ibadah) dan keluhuran pribadi (akhlakul karimah).

Pendidikan karakter seharusnya berangkat dari konsep dasar manusia: fitrah. Setiap anak dilahirkan menurut fitrahnya, yaitu memiliki akal, nafsu (jasad), hati dan ruh. Konsep inilah yang sekarang lantas dikembangkan menjadi konsep multiple intelligence. Dalam Islam terdapat beberapa istilah yang sangat tepat digunakan sebagai pendekatan pembelajaran. Konsep-konsep itu antara lain: tilâwah, ta'lîm', tarbiyah, ta'dîb, tazkiyah dan tadlrîb. Tilâwah menyangkut kemampuan membaca; ta'lim terkait dengan pengembangan kecerdasan intelektual (intellectual quotient); tarbiyah menyangkut kepedulian dan kasih sayang secara naluriah yang didalamnya ada asah, asih dan asuh; ta'dîb terkait dengan pengembangan kecerdasan emosional (emotional quotient); tazkiyah terkait dengan pengembangan kecerdasan spiritual (spiritual quotient); dan tadlrib terkait dengan kecerdasan fisik atau keterampilan (physical quotient atau adversity quotient). pembelajarannya dapat dicermati dalam gambar di bawah ini ${ }^{11}$.

Pendidik yang hakiki adalah Allah, guru adalah penyalur hikmah dan berkah dari Allah kepada anak didik. Tujuannya adalah agar anak didik mengenal dan bertaqwa kepada Allah, dan mengenal fitrahnya sendiri. Pendidikan adalah bantuan untuk menyadarkan, membangkitkan, menumbuhkan, memampukan dan memberdayakan anak didik akan potensi fitrahnya ${ }^{12}$.

Untuk mengembangkan kemampuan membaca, dikembangkan metode tilawah tujuannya agar anak memiliki kefasihan berbicara dan kepekaan dalam melihat fenomena. Untuk mengembangkan potensi fitrah

11 . Tobroni, Pendidikan Islam, Paradigma Teologis, Filosofis dan Spiritualitas Malang: UMM Press, 2008. $\mathrm{ttl}$

${ }^{12}$ Badr Azimabadi, Etiquettes of Islamic Life. (Kuala Lumpur: Adam Publisher and Distributors, 2000). hlm 30 
berupa akal dikembangkan metode ta'lîm, yaitu sebuah metode pendidikan ilmu pengetahuan dan teknologi yang menekankan pada pengembangan aspek kognitif melalui pengajaran. Dalam pendidikan akal ini sasarannya adalah terbentuknya anak didik yang memiliki pemikiran jauh ke depan, kreatif dan inovatif.

Sedangkan output-nya adalah anak yang memiliki sikap ilmiah, ulûl albâb dan mujtahid. Ulul Albab adalah orang yang mampu mendayagunakan potensi pikir (kecerdasan intelektual/IQ) dan potensi dzikimya untuk memahami fenomena ciptaan Tuhan dan dapat mendayagunakannya untuk kepentingan kemanusiaan. Sedangkan mujtahid adalah orang mampu memecahkan persoalan dengan kemampuan intelektualnya. Hasilnya yaitu ijtihad (tindakannya) dapat berupa ilmu pengetahuan maupun teknologi. Outcome dari pendidikan akal (IQ) terbentuknya anak yang saleh (waladun shalih) ${ }^{13}$.

Pendayagunaan potensi pikir dan zikir yang didasari rasa iman pada gilirannya akan melahirkan kecerdasan spiritual (spiritual quotient/SQ). Dan kemampuan mengaktualisasikan kecerdasan spiritual inilah yang memberikan kekuatan kepada guru dan siswa untuk meraih prestasi yang tinggi.

\section{Penggunaan Metode-Metode Pendidikan Karakter dalam Pendidikan Islam.}

Adapun metode yang digunakan adalah sebagai berikut:

1. Metode tarbiyah digunakan untuk membangkitkan rasa kasih sayang, kepedulian dan empati dalam hubungan interpersonal antara guru dengan murid, sesama guru dan sesama siswa. Implementasi metode tarbiyah dalam pembelajaran mengharuskan seorang guru bukan hanya sebagai pengajar atau guru mata pelajaran, melainkan seorang bapak atau ibu yang memiliki kepedulian dan hubungan interpersonal yang baik dengan siswa-siswinya. Kepedulian guru untuk menemukan

${ }^{13}$ Badr Azimabadi, Etiquettes of Islamic Life.( Kuala Lumpur: Adam Publisher and Distributors, 2000). HIm 37-41 


\section{Fatma Raudhah}

dan memecahkan persoalan yang dihadapi siswanya adalah bagian dari penerapan metode tarbiyah.

2. Metode ta'dîb digunakan untuk membangkitkan "raksasa tidur", kalbu (EQ) dalam diri anak didik. Ta'dîb lebih berfungsi pada pendidikan nilai dan pengembangan iman dan taqwa. Dalam pendidikan kalbu ini, sasarannya adalah terbentuknya anak didik yang memiliki komitmen moral dan etika. Sedangkan out put-nya adalah anak yang memiliki karakter, integritas dan menjadi mujaddid. Mujaddid adalah orang yang memiliki komitmen moral dan etis dan rasa terpanggil untuk memperbaiki kondisi masyarakatnya. "Banyak orang pintar tetapi tidak menjadi pembaharu (mujaddid). Seorang pembaharu itu berat resikonya. Menjadi pembaharu itu karena panggilan hatinya, bukan karena kedudukan atau jabatannya".

3. Metode tazkiyah digunakan untuk membersihkan jiwa (SQ). Tazkiyah lebih berfungsi untuk mensucikan jiwa dan mengembangkan spiritualitas. Dalam pendidikan Jiwa sasarannya adalah terbentuknya jiwa yang suci, jernih (bening) dan damai (bahagia). Sedang outputnya adalah terbentuknya jiwa yang tenang (nafs al-mutmainnah), ulûl arhâm dan tazkiyah. Ulûl arhâm adalah orang yang memiliki kemampuan jiwa untuk mengasihi dan menyayangi sesama sebagai manifestasi perasaan yang mendalam akan kasih sayang Tuhan terhadap semua hamba-Nya. Tazkiyah adalah tindakan yang senantiasa mensucikan jiwanya dari debu-debu maksiat dosa dan tindakan sia-sia (kedlaliman).

4. Metode tadlrib (latihan) digunakan untuk mengembangkan keterampilan fisik, psikomotorik dan kesehatan fisik. Sasaran (goa) dari tadlrib adalah terbentuknya fisik yang kuat, cekatan dan terampil. Output-nya adalah terbentuknya anaknya yang mampu bekerja keras, pejuang yang ulet, tangguh dan seorang mujahid. Mujahid adalah orang yang mampu memobilisasi sumber dayanya untuk mencapai tujuan tertentu dengan kekuatan, kecepatan dan hasil maksimal. ${ }^{14}$

${ }^{14}$ Tobroni, Pendidikan Islam, Paradigma Teologis, Filosofis dan Spiritualitas, ( Malang: UMM Press), 2008. ttl. 
Sebenarnya metode pembelajaran yang digunakan di sekolah lebih banyak dan lebih bervariasi yang tidak mungkin semua dikemukakan di sini secara detail. Akan tetapi pesan yang hendak dikemukakan di sini adalah bahwa pemakaian metode pembelajaran tersebut adalah suatu bentuk "mission screed" yaitu sebagai penyalur hikmah, penebar rahmat Tuhan kepada anak didik agar menjadi anak yang saleh. Semua pendekatan dan metode pendidikan dan pengajaran (pembelajaran) haruslah mengacu pada tujuan akhir pendidikan yaitu terbentuknya anak yang berkarakter taqwa dan berakhlak budi pekerti yang luhur. Metode pembelajaran dikatakan mengemban misi suci karena metode sama pentingnya dengan substansi dan tujuan pembelajaran itu sendiri. Dalam jargon pendidikan dikatakan: althariqatu ahammu min al-maddah, wa al-ustadzu ahammu min al-thariqah.

\section{Penutup}

Dalam pembangunan karakter terdapat beberapa problematika, di antaranya adalah memudarnya nasionalisme dan jati diri bangsa, merosotnya harkat dan martabat bangsa, mentalitas bangsa yang buruk, krisis multidimensial, dan degradsi moral perusak bangsa.

Solusi pembangunan karakter adalah meningkatkan rasa kebangsaan dan kesadaran berbangsa, penerapan pendidikan karakter dalam Pendidikan Islam, penggunaan metode-metode pendidikan karakter dalam Pendidikan Islam.

Metode yang digunakan adalah: pertama, metode tarbiyah yang digunakan untuk membangkitkan rasa kasih sayang, kepedulian dan empati dalam hubungan interpersonal antara guru dengan murid, sesama guru dan sesama siswa. Kedua, metode ta'dîb digunakan untuk membangkitkan "raksasa tidur", kalbu (EQ) dalam diri anak didik. Ta'dîb lebih berfungsi pada pendidikan nilai dan pengembangan iman dan taqwa. Ketiga, metode tazkiyah digunakan untuk membersihkan jiwa (SQ). Tazkiyah lebih berfungsi untuk mensucikan jiwa dan mengembangkan spiritualitas. Keempat, metode tadlrîb (latihan) digunakan untuk mengembangkan keterampilan fisik, psikomotorik dan kesehatan fisik. Sasaran (goa) dari tadlrîb adalah terbentuknya fisik yang kuat, cekatan dan terampil. 


\section{Daftar Pustaka}

Badr Azimabadi, Etiquettes of Islamic Life. Kuala Lumpur: Adam Publisher and Distributors, 2000.

Basari, Hasan / Bernhard Dahm, Sukarno dan perjuangan kemerdekaan, Jakarta : LP3ES, 1987. Judul asli : Sukarno and the struggle for Indonesia

Hadi, H., Nation and Character Building Melalui Pemahaman Wawasan Kebangsaan, Direktorat Politik, Komunikasi, dan Informasi Bappenas.

Heri Gunawan, Pendidikan Karakter Konsep dan Implementasi. (Bandung: Alfabeta, 2012),

Koentjaraningrat, Kebudayaan Mentalitas dan Pembangunan, Jakarta: Gramedia, 2002.

Tobroni, Pendidikan Islam, Paradigma Teologis, Filosofis dan Spiritualitas, Malang: UMM Press, 2008

-------, The Spiritual Leadership, Mengefektifkan Organisasi Noble Industri Melalui Prinsip-Prinsip Spiritual Etis, Malang: UMM Press, 2010.

-------, Rekonstruksi Pendidikan Agama untuk Membangun Etika Sosial dalam Kehidupan Berbangsa dan Bernegara, Malang: UMM Press, 2010

Thomas Lichona, www.cortland.edu/character/aboutus.html.

Yahya Khan, Pendidikan Karakter Berbasis Potensi Diri, (Yogyakarta: Pelangi Publishing, 2010. 